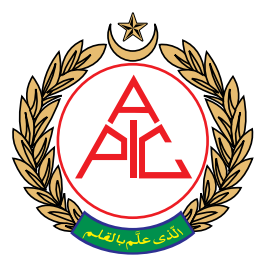

\title{
Development and implementation of a regional anesthetic service by general anesthesiologists for total joint arthroplasty patients in a small community hospital in the United States
}

\author{
David P. VanEenenaam ${ }^{1}$, Kathleen N. Johnson, BS ${ }^{1}$, \\ Hannah M. Harris, BS ${ }^{1}$, Jungbin A. Choi, BA ${ }^{1}$, \\ Matthew W. Bullock, DO ${ }^{2}$, Daniel J. Forest, MD ${ }^{1}$, Yvon F. Bryan, MD ${ }^{3}$
}

\begin{abstract}
${ }^{1}$ Department of Anesthesiology, Wake Forest School of Medicine, WinstonSalem, NC, (USA)

${ }^{2}$ Marshall Orthopedics, Marshall University Medical Center, Huntington, WV, (USA) ${ }^{3}$ Department of Anesthesiology, DartmouthHitchcock Medical Center Lebanon, New Hampshire, (USA)

Correspondence: Yvon F. Bryan, MD Department of Anesthesiology DartmouthHitchcock Medical Center 1 Medical Center Drive Lebanon, NH 03766 (USA)

Telephone: 603-650-6719

Email: yvon.f.bryan@hitchcock. org

yvon.f.bryan@dartmouth.edu Received: 25 September 2019,

Reviewed: 7 October 2019,

Accepted: 8 October 2019
\end{abstract}

\begin{abstract}
Background \& Objective: Regional anesthesia (RA) blocks are most commonly performed in large academic hospitals and has been shown to reduce postoperative pain. The lack of RA blocks in rural hospitals leaves a large subset of the population without availability of this service. In North Carolina, there is an increased need for these services in small community hospitals. This study examined RA nerve block success rates for total knee, hip, and shoulder arthroplasty procedures. We hypothesized that through proper mentorship, general anesthesiologists could provide safe and efficacious RA blocks at a small, community hospital.
\end{abstract}

Methodology: An Institutional Review Board (IRB) approved retrospective study was performed at Lexington Medical Center (LMC), in Lexington, North Carolina part of Wake Forest Baptist Health. We analyzed 307 patients who underwent total joint arthroplasty (195 knee, 69 hip and 43 shoulder replacements) at LMC. Demographics, type of blocks, block success, and intraoperative analgesics used were also recorded. VAS was used to assess postoperative pain.

Results: We found an overall success rate of $96.3 \%$ for all joints; $95.2 \%$-femoral or 98.9\%-adductor canal, 90.4\%-lumbar plexus, 100\%-interscalene block for knee, hip and shoulder arthroplasties respectively. 283/307 (92.2\%) patients reported a verbal pain score between $0-2$ in the PACU. There was a significantly higher mean fentanyl dose/h in patients that did not receive a lumbar plexus block for hip procedures.

Conclusion: The results of our study support that general anesthesiologists can provide rural communities with quality, specialized regional anesthesia care safely, and at an equivalent level to that of anesthesiologists specialized in RA blocks at large academic institutions.

Key words: Regional anesthesia; Total joint replacement; Arthroplasty; Nerve block

Citation: VanEenenaam DP, Johnson KN, Harris HM, Choi JA, Bullock MW, Forest DJ, Bryan YF. Development and implementation of a regional anesthetic service by general anesthesiologists for total joint arthroplasty patients in a small community hospital in the United States. Anaesth pain \& intensive care 2019;23(3):250-255

\section{INTRODUCTION}

Total joint arthroplasty (TJA), including total knee arthroplasty (TKA), total hip arthroplasty (THA), and total shoulder arthroplasty (TSA), is a common procedure to reduce pain and improve mobility., ${ }^{1,2}$ Many different anesthetic techniques are performed for TJA. Common anesthetic techniques include general 
anesthesia (GA), neuraxial anesthesia (NA), and/or regional anesthesia (RA) or a combination of these. ${ }^{3}$ The type of anesthesia performed depends on the type of procedure, patient comorbidities, and/or the training of the anesthesiologist. The use of RA, as opposed to GA, may reduce postoperative pain, nausea and/or vomiting, as well as disorientation and delirium. ${ }^{4,5}$ There are a variety of blocks that may be performed for each type of total joint surgery: adductor canal block (ACB) and femoral nerve block (FNB) for TKA, lumbar plexus block (LPB) and fascia iliaca block (FIB) for THA, and interscalene block (ISB) for TSA. ${ }^{6-8}$ The majority of studies performed to evaluate the use of different RA blocks for TJA patients were in academic and/or tertiary care centers. Few studies were performed in community hospitals, even though $80.2 \%$ of these surgeries were performed at these community hospitals. ${ }^{3}$

In general, access to specialized care may be limited in rural areas. In North Carolina, only one out of 31 physicians will enter a rural primary care practice. ${ }^{9}$ As the majority of North Carolina residents live in or near rural areas, there is a greater emphasis on the need for specialized care. In the most rural counties, there are only 10 physicians per 10,000 citizens. ${ }^{10}$ Since most rural hospitals are staffed by general anesthesiologists, the likelihood of the use of RA for TJA may be reduced. Patients in rural hospitals may have improved outcomes if provided with the resources to perform RA safely. However, implementation of new and unfamiliar techniques may require training not only of physicians but nurses and ancillary personnel as well.

This study examined patients undergoing total knee, hip and shoulder arthroplasties at Lexington Medical Center (LMC), a 94-bed rural community hospital in Lexington, North Carolina. ${ }^{3}$ LMC, a Wake Forest Baptist Health-affiliated hospital, is primarily staffed by general anesthesiologists with little to no training in RA techniques. An RA protocol was developed and implemented for general anesthesiologists to utilize in patients undergoing total knee, hip, and shoulder procedures. Fellowship-trained anesthesiologists mentored generalists in RA techniques. All the nurses were simultaneously trained in sedation and patient monitoring as well as in administering of local anesthetics and on the fundamentals of peripheral nerve stimulation and ultrasound equipment. Our goal was to develop, implement and evaluate the safety and efficacy of a RA block service in a rural hospital in the United States.

\section{METHODOLOGY}

A Wake Forest University Health Sciences Institutional Review Board (IRB) approved retrospective study was performed at LMC, part of Wake Forest Baptist Health. This study included all patients, over the age of 18, who underwent a total knee, hip, or shoulder arthroplasty from July 2016 to June 2017.
Prior to this retrospective study, RA blocks were performed at LMC in 2015. Fellowship-trained anesthesiologists at LMC mentored generalists in RA techniques. Nurses were also trained in sedation, monitoring, and ultrasound and nerve stimulation techniques. A checklist and quality initiative were developed to facilitate the safety of these procedures (Appendix 1) and allowed improvement by monitoring and documentation of RA blocks using a quality data collection document (Appendix 2).

The following demographic data were recorded: age, weight, height, body mass index (BMI), gender, and ASA status. Diagnosis, anesthetic technique, type of blocks, block medications, intraoperative fentanyl and/ or other analgesics administered, and postoperative pain score were also recorded. Intraoperative fentanyl dose was calculated as $\mu \mathrm{g} / \mathrm{kg} / \mathrm{h}$. Aborted blocks were defined as those that required multiple attempts by multiple clinicians and not completed. Failed blocks were defined as those that were placed and deemed ineffective upon postoperative evaluation.

Data were then compiled using RedCap data processing software.

\section{Statistical Analysis:}

The mean, standard deviation (SD), and range were calculated for demographic data. Two-sample, twotailed t-tests were performed to compare demographic data between success and failed blocks for TKA and THA. A Chi-squared test was performed to compare ASA classification and gender between success and failed blocks for TKA and THA. A p-value of less than 0.05 was considered statistically significant.

\section{RESULTS}

\section{Demographics}

See Table 1 for demographics and diagnoses.

\section{Type of Blocks}

Figures 1 and 2 depict the anesthetic techniques performed for TKA and THA patients, respectively. All (43/43) of TSA patients received an ISB and GA.

\section{Block Success}

A block was attempted in 300/307 (97.7\%) patients. Of the 300 attempted blocks, 6 were aborted and 5 failed upon evaluation, leaving a $96.3 \%$ overall success rate of blocks. Of the 11 failed blocks, 6 were from TKA and 5 were from THA.

\section{Total Knee Arthroplasty}

A block was attempted in 194/195 (99.5\%) patients. Of the 194 attempted blocks, $1(0.5 \%)$ was aborted and $5(2.6 \%)$ failed upon evaluation. There was a $96.9 \%$ $(188 / 194)$ success rate. Of the 6 unsuccessful blocks, 
regional anesthetic service for total joint arthroplasty

Table 1: Demographic data presented as Mean \pm SD (Range)

\begin{tabular}{|c|c|c|c|c|}
\hline & TJA $(\mathrm{N}=307)$ & TKA $(\mathrm{N}=195)$ & THA $(N=69)$ & $\mathrm{TSA}(\mathrm{N}=43)$ \\
\hline $\begin{array}{l}\text { Age (y) } \\
\text { Weight }(\mathrm{kg}) \\
\text { Height }(\mathrm{m}) \\
\text { BMl }(\mathrm{kg} / \mathrm{m} 2)\end{array}$ & $\begin{array}{c}67 \pm 10.0(31-90) \\
90 \pm 20.5(43.5-155.1) \\
1.7 \pm .10(1.5-2.0 \\
31.2 \pm 6.5(18.8-56.1)\end{array}$ & $\begin{array}{c}67 \pm 9.8(41-90 \\
91 \pm 19.5(52.2-155.1) \\
1.7 \pm .10(1.5-2.0) \\
31.5 \pm 6.4(20.3-56.1)\end{array}$ & $\begin{array}{c}67 \pm 11.0(31-89) \\
87 \pm 22.1(43.5-145.6) \\
1.7 \pm .1(1.5-2.0) \\
29.8 \pm 6.2(18.8-53.4)\end{array}$ & $\begin{array}{c}69 \pm 9.2(48-87) \\
89 \pm 22.1(49-149.7) \\
1.7 \pm .10(1.5-1.9) \\
32.2 \pm 7.4(21.3-50.3)\end{array}$ \\
\hline & \multicolumn{4}{|c|}{ Gender N (\%) } \\
\hline \multirow[t]{2}{*}{$\begin{array}{l}\text { Male } \\
\text { Female }\end{array}$} & $\begin{array}{l}141(45.9) \\
166(54.1)\end{array}$ & $\begin{array}{c}87(44.6) \\
108(55.4)\end{array}$ & $\begin{array}{l}33(47.8) \\
3652.2)\end{array}$ & $\begin{array}{l}21(48.8) \\
22(51.2) \\
\end{array}$ \\
\hline & \multicolumn{4}{|c|}{ ASA Status N (\%) } \\
\hline \multirow[t]{2}{*}{$\begin{array}{l}\text { I-II } \\
\text { III-IV }\end{array}$} & $\begin{array}{l}136(44.3) \\
171(55.7)\end{array}$ & $\begin{array}{c}91(46.7) \\
104(53.3)\end{array}$ & $\begin{array}{l}34(49.3) \\
35(50.7)\end{array}$ & $\begin{array}{l}11(25.6) \\
32(73.4)\end{array}$ \\
\hline & \multicolumn{4}{|c|}{ Diagnosis N (\%) } \\
\hline $\begin{array}{l}\text { Arthritis } \\
\text { Necrosis } \\
\text { Rotator Cuff Tear } \\
\text { Fracture } \\
\text { Other }\end{array}$ & $\begin{array}{c}256(83.4) \\
7(2.3) \\
22(7.2) \\
9(2.9) \\
13(4.2)\end{array}$ & $\begin{array}{c}182(93.3) \\
2(1.0) \\
0(0.0) \\
1(0.5) \\
10(5.1)\end{array}$ & $\begin{array}{c}64(92.8) \\
4(5.8) \\
0(0.0) \\
0(0.0) \\
1(1.4)\end{array}$ & $\begin{aligned} 10 & (23.3) \\
1 & (2.3) \\
22 & (51.2) \\
8 & (18.6) \\
2 & (4.7)\end{aligned}$ \\
\hline
\end{tabular}

TJA - total joint arthroplasty; TKA -total knee arthroplasty; THA - total hip arthroplasty; TSA - total shoulder arthroplasty

$5(83.3 \%)$ were FNB (including the aborted block) and $1(16.6 \%)$ was an ACB. There was a 95.2\% (99/104) success rate for FNBs and a 98.9\% (89/90) success rate for ACBs. The mean age of patients who received a successful block was $66.9 \mathrm{yr}$ and failed blocks 56.7 $\mathrm{yr}(\mathrm{p}$-value $=0.01)$. There were no other significant differences in the other demographic data or fentanyl dose between the successful and failed blocks.

\section{Total Hip Arthroplasty}

A block was attempted in 63/69 (91.3\%) patients. Of the 63 attempted blocks, $6(9.5 \%)$ were aborted. One of the aborted blocks switched to a different block (LPB to FIB). There was a $92.1 \%(58 / 63)$ success rate. There was a $90.4 \%(57 / 63)$ success rate for LPBs. One FIB was attempted and deemed successful. There were no significant differences in demographic data between the successful blocks and the failed blocks. The mean fentanyl dose $/ \mathrm{h}$ for successful blocks was $0.08 \mu \mathrm{g} / \mathrm{kg} / \mathrm{h}$ and that of aborted LPBs was $0.51 \mu \mathrm{g} / \mathrm{kg} / \mathrm{h}$ (p-value $=$ $\left.2.8 \times 10^{-7}\right)$.

\section{Total Shoulder Arthroplasty}

A block was attempted in 43/43 (100\%) patients. There was a $100 \%$ success rate of ISBs. Although all blocks were eventually successful, 1 (2.3\%) block had to be repeated preoperatively.

\section{Pain Scores}

See Table 2 for pain scores.

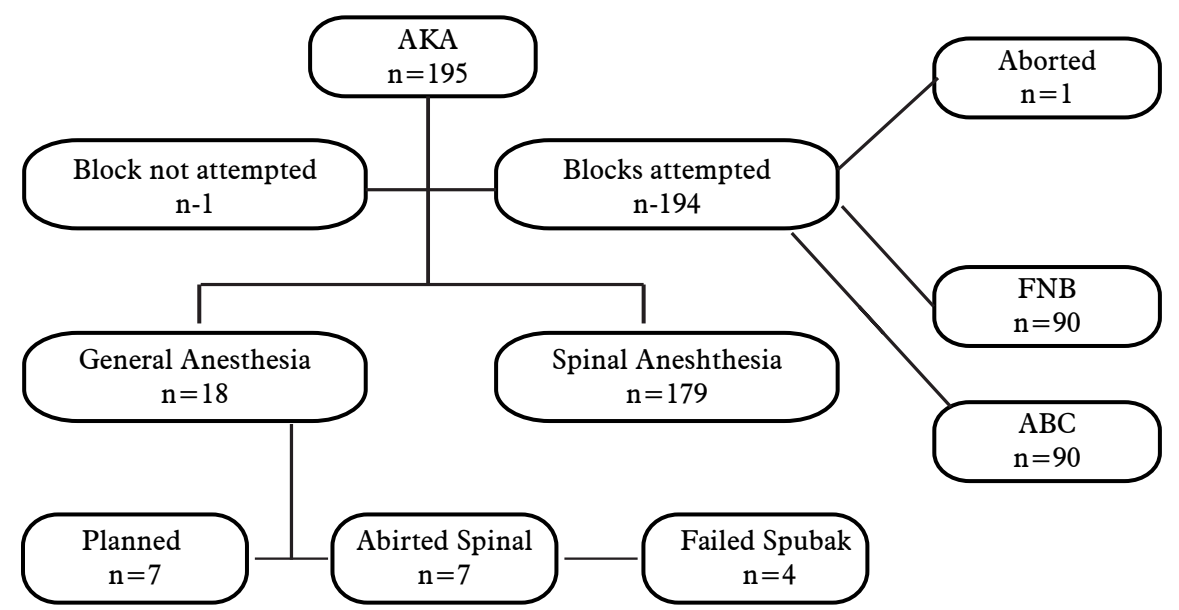

Figure 1: The anesthetic technique for total knee arthroplasty patients. The GA cases were divided into those that were planned general (no spinal was attempted), an aborted spinal (spinal attempted, but not placed), and failed spinal (spinal placed and deemed ineffective, requiring GA). $T K A=$ total knee arthroplasty, FNB = femoral nerve block, $A C B=$ adductor canal block.

\section{DISCUSSION}

We found a high success rate of RA blocks performed by general anesthesiologists at LMC. However, failures were reported with FNB, ACB, and LPB. LPBs were aborted most frequently compared to the other blocks. We found that patients who had aborted LPBs required more fentanyl intraoperatively, and that failed TKA blocks tended to occur in younger patients. These findings support our hypothesis that specialized RA blocks may be performed safely by general anesthesiologists in a rural area. 


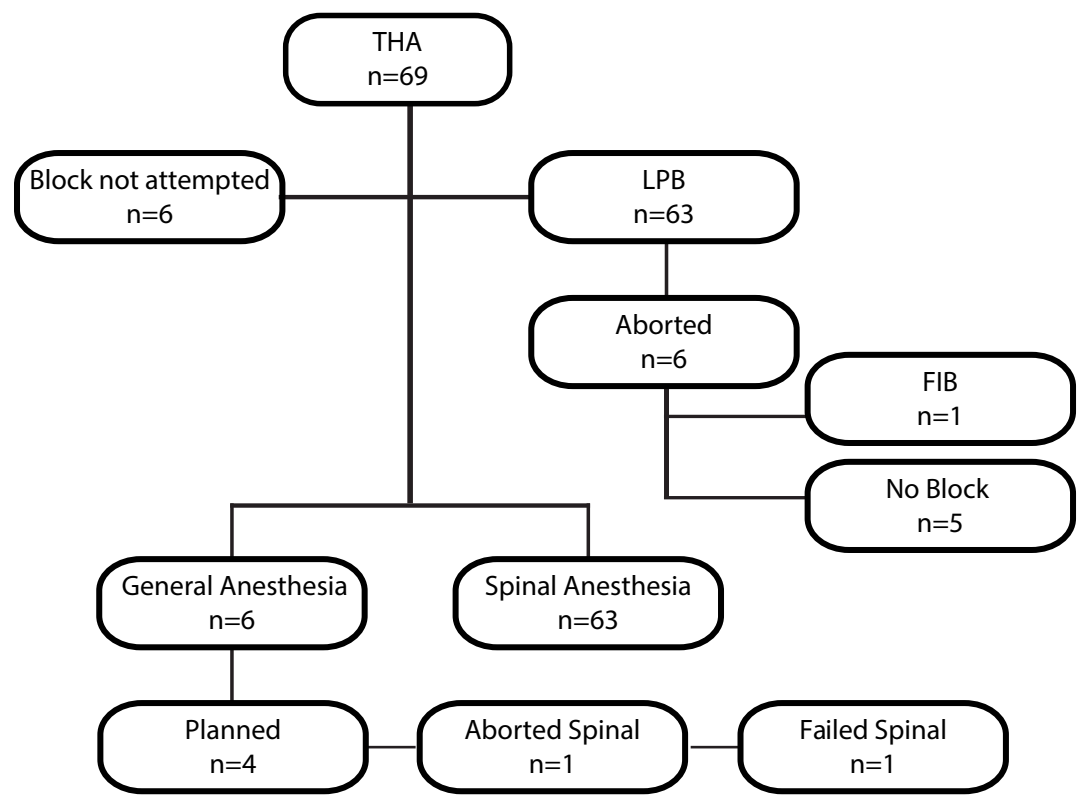

Figure 2: The anesthetic technique for THA patients. The GA cases were divided into those that were planned general (no spinal was attempted), an aborted spinal (spinal attempted, but not placed), and failed spinal (spinal placed and deemed ineffective, requiring GA). THA = total hip arthroplasty, $L P B=$ lumbar plexus block, FIB = fascia iliaca block.

Bakker et al. conducted a review of the success rate of the ISB during TSA and found $94.3 \%$ of their blocks were successful. ${ }^{8}$ Though this study was performed in a larger hospital, outside of the US, involving a greater number of patients, our ISB success rate in Lexington was comparable. Similarly, Shah et al. evaluated the success of ACB and FNB for TKA in 100 patients and found $96 \%$ and $100 \%$ success rates, respectively, which were very similar to those of our study. ${ }^{7}$ Though our success rates for LPB were notably lower than success rates for other blocks, we had a greater success rate than that found in Luber et al. despite performing the blocks in a rural hospital. ${ }^{6}$

While our study did not report any fatalities or cardiac arrests, it has been shown that LPBs can induce respiratory failure, cardiac arrest, and/or death. ${ }^{13}$ In addition, it is difficult to produce an adequate spread, which may result in lower success rates of the LPB. ${ }^{14}$ The most common difficulty associated with

The demographics of our patients were comparable to similar studies focused on rural populations and TJA outcomes. ${ }^{11}$ Their study found that TJA patients in rural areas were younger than those in metropolitan areas. ${ }^{11}$ Since our patients were of similar age, we may assume that our patients presented for TJA earlier than patients typically do in urban areas of the country. This may have been due to the lack of access to more specialized care, such as rheumatology services, which may have forced patients in rural areas to undergo surgery before seeking other treatments. ${ }^{11}$ While RA blocks are used less frequently in rural hospitals, Fleischut et al. found the use of NA and RA blocks have risen since $2010 .^{3}$ More specifically, Cozowicz et al. found a $4.5 \%$ and $10.2 \%$ increase in NA and PNB utilization, respectively, in rural hospitals from 2006-2013. ${ }^{12}$ Our development of a RA service in LMC supports these findings. We also found our block success to be comparable or more successful than other studies examining block success.

Table 2: PACU pain scores [data given as $\mathbf{n}(\%)$ ]

\begin{tabular}{l|c|c|c|c}
\hline Verbal Pain Score & TJA $(\mathbf{N = 3 0 7 )}$ & TKA $(\mathbf{N = 1 9 5 )}$ & THA (N=69) & TSA (N=43) \\
\hline $0-2$ & $283(92.2)$ & $178(91.3)$ & $63(91.3)$ & $42(97.7)$ \\
\hline $3-5$ & $17(5.5)$ & $11(5.6)$ & $5(7.2)$ & $1(2.3)$ \\
\hline $6-10$ & $7(2.3)$ & $6(3.1)$ & $1(1.4)$ & $0(0.0)$ \\
\hline
\end{tabular}

TJA - total joint arthroplasty; TKA -total knee arthroplasty; THA - total hip arthroplasty; TSA - total shoulder arthroplasty
LPB is epidural diffusion which produces complication rates between $1-16 \% .{ }^{14}$ The high range of complications and lower degree of successful block placement may suggest that the use of an alternative block for THA, such as the FIB may be beneficial. ${ }^{15}$ After this study was completed, a patient suffered a cardiac arrest, necessitating a left ventricular assist device (LVAD) after a lumbar plexus block was placed. ${ }^{16}$ The patient was discharged home without any complications several days after the cardiac arrest. ${ }^{16}$ Due to the lower LPB success rate found in this study, LMC has since decreased its use and increased the use of the FIB. We found our LPB failures to have statistically significant differences in intraoperative fentanyl doses, with the higher doses of fentanyl in patients who had aborted blocks. We hypothesized that patients who did not receive a block required greater pain control through the administration of other analgesics during the procedure. In addition, we also found our patients undergoing TKA who had failed blocks to be significantly younger than those who received a successful block. We hypothesized that this may be due to the tendency of rural populations to participate in manual or agricultural labor. ${ }^{11}$ There is a significant amount of increased strain placed on the joints of these patients, leading to earlier degradation. This may 
cause increased complications at younger ages, which, due to increased muscle mass, could result in a higher frequency of failed blocks.

\section{LIMITATIONS}

Our study had several limitations. This was a retrospective study; therefore, follow-up data could not be obtained with regards to postoperative pain and complications. Also, it was difficult to determine the specific reasons why the RA blocks failed. Another limitation was that the study involved a single, small rural hospital in Lexington, North Carolina with a relatively small number of cases to examine, so the sample size was low. Future studies should be performed on the use of RA for TJA patients in other rural hospitals.

\section{CONCLUSION}

In conclusion, we found that specialized RA blocks may be performed in a safe and efficacious manner by general anesthesiologists in a small rural hospital. When general anesthesiologists were mentored by regionally trained anesthesiologists, the outcomes for basic RA blocks were comparable to those in large, academic hospitals. Our training procedures and infrastructure for research may be used as a model for other rural institutions. Furthermore, this study supports the notion that rural hospitals should increase their offering of specialized forms of care to minimize the need for patients and families to travel away from home and receive care similar to large metropolitan areas.

\section{Acknowledgments:}

None of the authors have conflict of interests to report. Financial support was received internally from the Department of Anesthesiology at Wake Forest Baptist Health.

Authors' contribution: All authors took part in preparation of this study.

Appendix 1: Regional Anesthesia Block Registered Nurse (RN) Training/Set-Up Training

\begin{tabular}{|c|c|}
\hline $\begin{array}{l}\text { TRAINING } \\
\text { Sedation } \\
\text { - Discuss medications used for sedation } \\
\text { - Discuss monitoring of patient vital signs } \\
\text { Monitoring } \\
\text { - Oxygen mask [5 L/min] } \mathrm{O}_{2} \\
\text { - BP - check every } 3 \text { min } \\
\text { - EKG } \\
\text { - Pulse oximeter - Set volume at } 7 / 10 \\
\text { - Capnography- Measure end tidal } \mathrm{CO}_{2} \\
\text { - Peripheral nerve stimulation } \\
\text { Ultrasound } \\
\text { - Adjust depth and gain } \\
\text { - Capture images for patient records } \\
\text { Local Anesthetics } \\
\text { - Recognize signs of local anesthetic toxicity } \\
\text { - Emulsification protocol available } \\
\text { - Discuss different local anesthetics }\end{array}$ & 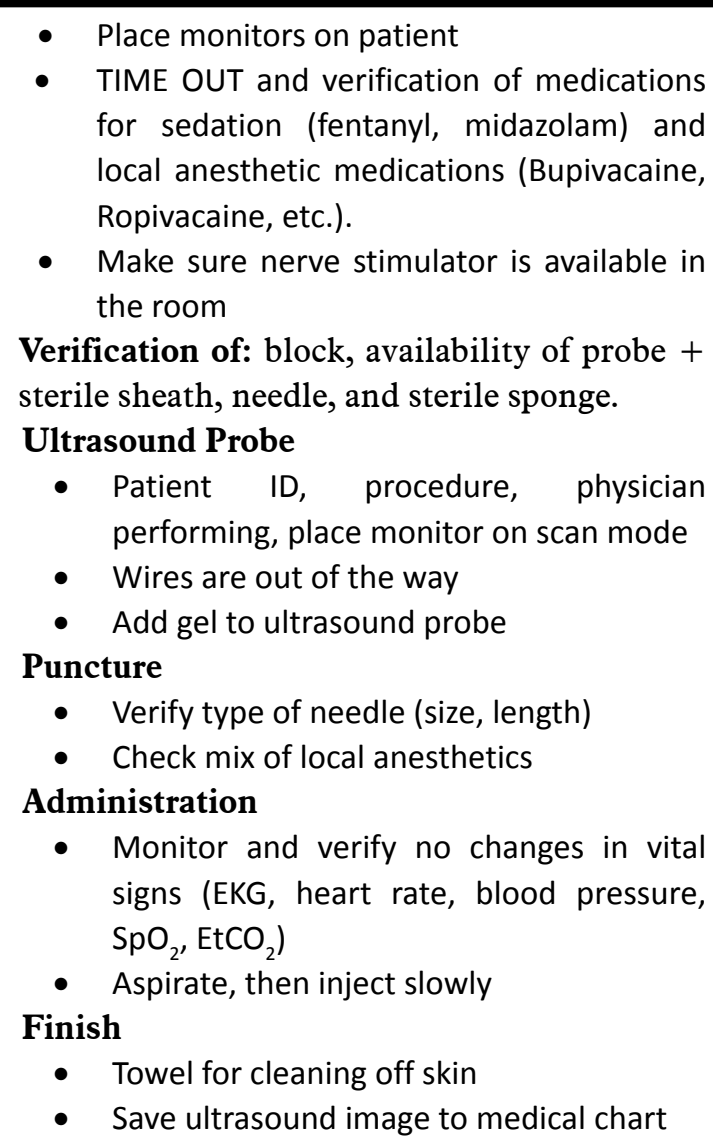 \\
\hline
\end{tabular}




\section{REFERENCES}

1. Macfarlane AJ, Prasad GA, Chan VW, Brull R. Does regional anaesthesia improve outcome after total hip arthroplasty? A systematic review. $\mathrm{Br} J$ Anaesth. 2009;103(3):335-45. [PubMed] DOI: 10.1093/bja/aep208

2. Melton MS, Monroe HE, Qi W, Lewis SL, Nielsen KC, Klein SM. Effect of interscalene brachial plexus block on the pulmonary function of obese patients: a prospective, observational cohort study. Anesth Analg. 2017;125(1):313-9. [PubMed] DOl: 10.1213/ANE.0000000000002180

3. Fleischut PM, Eskreis-Winkler JM, Gaber-Baylis LK, Giambrone GP, Faggiani SL, Dutton RP, et al. Variability in anesthetic care for total knee arthroplasty: an analysis from the anesthesia quality institute. Am J Med Qual. 2015;30(2):172-9. [PubMed] DOI: $10.1177 / 1062860614525989$

4. Al Harbi M, Kaki AM, Kamal A, ElDawlatly A, Daghistani M, El Tahan MR. A survey of the practice of regional anesthesia in Saudi Arabia. Saudi J Anaesth. 2013;7(4):36770. [PubMed] DOI: $10.4103 / 1658-$ 354X.121041

5. Moller JT, Cluitmans $P$, Rasmussen LS, Houx P, Rasmussen $H$, Canet $J$, et al. Long-term postoperative cognitive dysfunction in the elderly ISPOCD1 study. ISPOCD investigators. international study of post-operative cognitive dysfunction. Lancet. 1998;351(9106):857-61. [PubMed] DOI: $10.1016 / \mathrm{s} 0140-$ $\underline{6736(97) 07382-0}$
6. Luber MJ, Greengrass R, Vail TP. Patient satisfaction and effectiveness of lumbar plexus and sciatic nerve block for total knee arthroplasty. J Arthroplasty. 2001;16(1):1721. [PubMed] DOI: 10.1054/ arth.2001.16488

7. Shah NA, Jain NP. Is continuous adductor canal block better than continuous femoral nerve block after total knee arthroplasty? Effect on ambulation ability, early functional recovery and pain control: a randomized controlled trial. J Arthroplasty. 2014;29(11):22249. [PubMed] DOI: 10.1016/i. arth.2014.06.010

8. Bakker SMK, Stienstra R. Improving Performance by Monitoring the Success Rate of Peripheral Nerve Blocks. Anesth Analg. 2018;126(2):644-647.

9. Irons TG, Sauer ML. Looking back but leaning forward: new opportunities and challenges for North Carolina's rural communities. N C Med J. 2018;79(6):366-71. [PubMed] DOI: 10.18043/ncm.79.6.366

10. Holmes M. The sufficiency of health care professional supply in rural North Carolina. N C Med J. 2018;79(6):3727. [PubMed] DOI: 10.18043/ ncm.79.6.372

11. Dowsey MM, Petterwood J, Lisik JP, Gunn J, Choong PF. Prospective analysis of rural-urban differences in demographic patterns and outcomes following total joint replacement. Aust J Rural Health. 2014;22(5):241-8.
[PubMed] D0I: $\underline{10.1111 / \text { ajr.12100 }}$

12. Cozowicz C, Poeran J, Zubizarreta $\mathrm{N}$, Mazumdar $\mathrm{M}$, Memtsoudis SG. Trends in the use of regional anesthesia: neuraxial and peripheral nerve blocks. Reg Anesth Pain Med. 2016;41(1):43-9. [PubMed] DOI: 10.1097/AAP.0000000000000342

13. Auroy Y, Benhamou D, Bargues L, Ecoffey C, Falissard B, Mercier FJ, et al. Major complications of regional anesthesia in France: The sos Regional Anesthesia Hotline Service. Anesthesiology. 2002;97(5):1274-80. [PubMed] DOI: 10.1097/00000542$\underline{200211000-00034}$

14. Capdevila X, Coimbra C, Choquet 0 . Approaches to the lumbar plexus: success, risks, and outcome. Reg Anesth Pain Med. 2005;30(2):15062. [PubMed] DOI: 10.1016/i. rapm.2004.12.007

15. Steenberg J, Moller AM. Systematic review of the effects of fascia iliaca compartment block on hip fracture patients before operation. Br J Anaesth. 2018;120(6):1368-80. [PubMed] DOI: $10.1016 /$ /.bja.2017.12.042

16. Bryan YF, Johnson KN, Harris HM, Cassidy AL. Stress-induced cardiomyopathy and need for left ventricular assist device in patient after lumbar plexus block: From LAST to Cath. Anesthesiology 2018. MC2849. Presented at American Society of Anesthesiologist's Annual Meeting 2018. 